\title{
Serum Vitamin D Level in Patients Undergoing Coronary Artery Catheterization
}

\author{
- Bikash Nepal ${ }^{1} \bullet$ Biplave Karki ${ }^{1} \bullet$ Jeet Prasad Ghimire ${ }^{1} \bullet$ Aditya Mahaseth ${ }^{1} \bullet$ Swapnil Pandit ${ }^{1} \bullet$ Ajit Sah $^{1}$ \\ - Surendra Uranw ${ }^{2} \bullet$ Naveen Kumar Pandey ${ }^{1} \bullet$ Prashant Shah $^{1} \bullet$ Prahlad Karki ${ }^{1}$ \\ Submitted 4 May 2021 \\ Bikash Nepal \\ bikashnepal52@gmail.com \\ (iD https://orcid.org/0000-0001-8189-2466 \\ ${ }^{1}$ Department of Cardiology \\ 2 Department of Internal Medicine, \\ B. P. Koirala Institute of Health Sciences, \\ Dharan.

\section{Citation} \\ "Nepal B, Karki B, Ghimire JP, Mahaseth A, Pandit \\ $S$, Sah A, et al. Serum vitamin D level in patients \\ undergoing coronary artery catheterization. \\ JBPKIHS. 2021;4(1):9-14. \\ doi https://doi.org/10.3126/jbpkihs.v4i1.37234

\section{(ब) $\Theta \Theta$} \\ This work is licensed under a Creative Commons Attribution \\ NonCommercial 4.0 International License. \\ Accepted 16 June 2021 \\ Published 30 June 2021 \\ Background: Vitamin $D$ deficiency may be a risk factor for coronary artery \\ disease (CAD). We aimed to measure the prevalence of vitamin $D$ deficiency \\ in $C A D$ and its association with severity \\ of angiographic proven CAD. \\ Methods: This prospective, cross-sectional study included 106 consecutive \\ patients who were admitted for typical angina and had signs of myocardial injury \\ (ECG findings and/ or elevated troponin I or CK-MB) and who underwent \\ coronary angiography at the university hospital of BPKIHS from August 2020 \\ to April 202I. Patients were categorized into angiographic proven CAD group \\ and angiographic normal coronary artery group. Serum vitamin $D$ level was \\ classified as normal ( $\geq 30 \mathrm{ng} / \mathrm{ml}$ ) and deficiency $(<30 \mathrm{ng} / \mathrm{ml})$. \\ Results: Out of 106 patients, 78 patients (73.6\%) had vitamin D deficiency \\ and $28(26.4 \%)$ had normal vitamin $D$ level $(p=0.39)$. Vitamin $D$ level (mean \\ $\pm S D$ ) in patients with angiographic normal coronary artery and angiographic \\ proven CAD were $25.94 \pm 11.63 \mathrm{ng} / \mathrm{ml}$ and $26.07 \pm 12.90 \mathrm{ng} / \mathrm{ml}$ respectively \\ $(P=0.97)$. Prevalence of vitamin $D$ deficiency was $75.0 \%$ and $64.3 \%$ in \\ significant $C A D$ group and normal coronary artery group respectively ( $P$ \\ $=0.39$ ). Similarly, frequency of vitamin $D$ deficiency were $68.6 \%, 78.3 \%$ and \\ $88.90 \%$ in single, double, and triple vessel disease respectively $(P=0.21)$. The \\ vitamin $D$ level (mean $\pm S D$ ) in single, double and triple vessel disease were \\ $27.3 \mathrm{I} \pm 14.02 \mathrm{ng} / \mathrm{ml}, 25.69 \pm 12.72 \mathrm{ng} / \mathrm{ml}, 23.08 \pm 9.45 \mathrm{ng} / \mathrm{ml}$ respectively. \\ Conclusion: The prevalence of vitamin $D$ deficiency in both angiographic \\ normal coronary artery and angiographic proven CAD were high but \\ comparable. There was no association of vitamin $D$ deficiency with severity of \\ angiographic proven CAD. \\ Keywords: Coronary angiography; Coronary artery disease; Vitamin D \\ deficiency

\section{Declarations} \\ Ethics approval and consent to participate: Ethical approval was ob- \\ tained from Institute Review Committee of B. P. Koirala Institute of Health Scienc- \\ es, Dharan (Ref no - 562/077/078-IRC) and informed consent has been obtained \\ from participants prior to the enrollment. \\ Consent for publication: Not applicable \\ Availability of data and materials: The full data set supporting this re- \\ search is submitted to the journal and available upon request by the readers. \\ Competing interest: None \\ sign, data collection, JPG: design, data collection, AM: design, data collection, SP: \\ design, data collection, AS: design, data collection, SU: data analysis, interpretation, \\ NKP: design, manuscript revision, PS: design, manuscript revsion, PK: manuscript \\ revision/ edit.All the authors have read and approved the final manuscript. \\ Acknowledgement:We would like to thank Dr. Prativa Chapagain Nepal for \\ providing assistance at all times during the study. Similarly, we appreciate the help \\ of cardiac catheterization laboratory staffs, biochemistry laboratory staffs, CCU \\ and cardiology ward nurses and staffs during the process of data collection.
}

Funding: None

Authors' contributions: BN: concept, data analysis, interpretation. BK: de- 
$\mathrm{C}$ oronary artery disease (CAD) is a leading cause of death despite significant progress in primary prevention and treatment strategies [1]. Although it has been associated with hypertension, diabetes mellitus, dyslipidemia and smoking, the search for newer preventable, modifiable risk factors continues in order to decrease cardiovascular morbidity and mortality [2]. Vitamin D deficiency is reported to be associated with cardiovascular disease (CVD) and many of its risk factors [3, 4].

Vitamin D is important in calcium and phosphate metabolism which facilitates bone mineralization, muscle contraction, nerve conduction and general cellular function [5]. Growing evidence suggests more diversified role of vitamin $\mathrm{D}$ than previously believed. Vitamin $\mathrm{D}$ deficiency has been shown to result in cardiac hypertrophy and fibrosis by elevation of matrix metalloproteinase enzyme [6, 7]. It also predisposes to hypertension by up regulation of the renin-angiotensin system [8]. Similarly, it is also involved in promoting the formation of atheromatous plaque by increasing the uptake of lipids by macrophages and their conversion into foam cells [4]. Hence, it's deficiency increases the risk of CVD and CAD.

Vitamin D deficiency is recognized as a major public health problem globally [5]. Its prevalence is up to $73 \%$ in Nepalese population and variably reported as $51.2 \%$ to $95 \%$ in CAD [9-11]. In South Asian population, CAD has an early onset and is aggressive [12]. However, only a few studies have explored the role of vitamin D deficiency in CAD patients and the results are conflicting. In this cross-sectional study, we aimed to measure prevalence of vitamin $\mathrm{D}$ deficiency in CAD and to assess association of vitamin $\mathrm{D}$ deficiency with angiographically proven $\mathrm{CAD}$.

\section{METHODS}

$\mathrm{T}$ his prospective, cross-sectional study was conducted at a university hospital of B. P. Koirala Institute of Health Sciences (BPKIHS), Dharan, Nepal from August 2020 to April 2021. All consecutive patients aged $\geq 20$ years visiting emergency department or cardiology out patient unit for typical angina and ECG showing signs of ischemia and/ or biomarker evidence of myocardial injury (elevated troponin I or creatine kinase-MB (CK-MB)) who underwent coronary angiography (CAG) were enrolled. Patients having severe valve disease, liver or kidney failure, diseases related to bone metabolism, primary or secondary hyperparathyroidism, malignancy or oste- oporosis, or taking vitamin D supplements or drugs like rifampicin, phenytoin, barbiturate, and thiazide diuretics which may interfere with vitamin D metabolism were excluded. Patients were recruited as per medical ethics and informed written consent was taken from each patient. Institutional Review Committee had approved the study protocol before recruitment of patients.

Sample size was estimated based on the prevalence of vitamin D deficiency in CAD as $51.2 \%$ as shown by a previous study [10]. Using $Z$ value of 1.96 for confidence interval of $95 \%$ with $80 \%$ power and precision of $10 \%$, the estimated sample size was 106 patients, including $10 \%$ dropout.

A detailed socio-demographic data and relevant clinical information were recorded in a structured data collection tool. All patients underwent thorough detailed medical history, clinical evaluation, blood sampling, electrocardiography (ECG) and echocardiography. All patients had undergone CAG as per American College of Cardiology American Heart Association (ACC/AHA) guidelines [13]. Random blood sugar (RBS), fasting blood sugar (FBS), post-prandial blood sugar (PPBS), glycosylated hemoglobin ( $\mathrm{HbA1c})$, renal function tests, lipid profile, troponin I and CK-MB of all patients were performed by standard methods. Blood samples for relevant baseline investigations were collected at the time of admission and before initiating medication. Samples for lipid profile and vitamin D were drawn after eight hours of fasting on the next day of admission.

The vitamin D level was determined by fully automated chemiluminescence immunoassay (CLIA) analyzer from Snibe Diagnostic MAGLUMI 2000 in the standard biochemistry laboratory. The principle of operation of vitamin D assay is a two-incubation chemiluminescence immunoassay. Two milliliters of blood was centrifuged at room temperature. Collected serum was incubated twice, after which the washed sample underwent chemiluminescent reaction to measure relative light units that gave the measure of $25-\mathrm{OH}$-vitamin D in serum. Vitamin D level $\geq 30 \mathrm{ng} / \mathrm{ml}$ was considered as normal whereas the level $<30 \mathrm{ng} / \mathrm{ml}$ as deficiency. Vitamin D levels between $20-30 \mathrm{ng} / \mathrm{ml}$ were considered as mild deficiency, $10-20 \mathrm{ng} / \mathrm{ml}$ as moderate deficiency and $<10 \mathrm{ng} / \mathrm{ml}$ as severe deficiency.

All 106 patients were grouped as angiographic proven $\mathrm{CAD}$ group and normal coronary artery group based on the CAG finding. Angiographic proven CAD was defined as coronary artery stenosis $\geq 50 \%$ in one or more major coronary arteries. It was further grad- 
ed as single vessel disease (SVD), double vessel disease (DVD) and triple vessel disease (TVD) depending upon the number of vessels involved. Angiographic normal coronary artery was defined as coronary artery luminal diameter narrowing $<50 \%$ or normal coronary artery.

\section{OPERATIONAL DEFINITIONS}

Case definition of CAD was based on the WHO European Acute Myocardial Infarction Registry criteria [14]. Hypertension was defined as per 2017 ACC/ AHA task force guideline [15]. Diabetes was defined as per 2017 American Diabetes Association guidelines [16]. Dyslipidemia was defined as per 2017 American Association of Clinical Endocrinologists guidelines [17]. Smokers were defined as anyone who has smoked 100 cigarettes in his or her lifetime and who currently smokes cigarettes [18].

The collected data was entered in Microsoft excel 2007 and uploaded into Statistical Package for Social Sciences version 17 (SPSS Inc; Chicago, IL, USA). Values were expressed as number, percentage, mean \pm standard deviation or median (IQR). The chi-square test was used to compare categorical variables and the Student's t-test was used to compare normally distributed data. A two-sided p-value of $<0.05$ was considered as statistically significant with $95 \%$ confidence interval.

\section{RESULTS}

ut of the 106 enrolled patients, 14 (13.2\%) had angiographic normal coronary artery. Among the 92 (86.8\%) patients with angiographic proven CAD, 51 (48.1\%) patients had SVD, 23 (21.7\%) had DVD and 18 (17.0\%) had TVD. Thirty-two patients (30.2\%) were diagnosed as chronic stable angina (CSA); 74 patients (69.8\%) as acute coronary syndrome (ACS). The age, gender distribution and presence of hypertension, diabetes mellitus, smoking and dyslipidemia was comparable between angiographic proven $\mathrm{CAD}$ and angiographic normal coronary artery groups. FBS, PPBS and HbA1c were significantly higher in patients with angiographic proven $\mathrm{CAD}$ compared to angiographic normal coronary artery group (Table 1).

The vitamin D level [median (IQR)] among the 106 patients was $22.75(18.41,31.01) \mathrm{ng} / \mathrm{ml}$ with minimum of $6.4 \mathrm{ng} / \mathrm{ml}$ and maximum of $78.85 \mathrm{ng} / \mathrm{ml}$. Both groups of patients with angiographic normal coronary artery and angiographic proven CAD had low vitamin D levels (Fig. 1).

Prevalence of vitamin D deficiency in 106 patients was $73.6 \%$. The prevalence of vitamin $\mathrm{D}$ deficiency in

\begin{tabular}{|c|c|c|c|}
\hline Parameters & $\begin{array}{l}\text { Angiographic normal coronary } \\
(n=14)\end{array}$ & Angiographic proven CAD $(n=92)$ & $p$-value \\
\hline Age $(y)$ & $62.14 \pm 10.51$ & $64.15 \pm 11.49$ & $0.5 \mathrm{I}^{\#}$ \\
\hline Male/ Female (57/ 49) & $9(15.8 \%) / 5(10.2 \%)$ & $48(84.2 \%) / 44$ (89.8\%) & $0.39 *$ \\
\hline ACS/ CSA (74/ 32) & $5(6.8 \%) / 9(28.1 \%)$ & $69(93.2 \%) / 23(71.9 \%)$ & 0.003 \\
\hline Diabetics $(n=36)$ & $2(5.6 \%)$ & 34 (94.4\%) & $0.09 *$ \\
\hline Hypertensive $(n=27)$ & $13(16.5 \%)$ & $66(83.5 \%)$ & $0.09 *$ \\
\hline Smoker $(n=38)$ & $4(10.5 \%)$ & 34 (89.5\%) & $0.54 *$ \\
\hline Alcoholic $(n=14)$ & $4(28.6 \%)$ & $10(71.4 \%)$ & $0.06 *$ \\
\hline Dyslipidemic $(n=15)$ & I (6.7\%) & 14 (93.3\%) & $0.41 *$ \\
\hline FBS $(\mathrm{mg} / \mathrm{dl})$ & $106 \pm 13.29$ & $120.26 \pm 38.10$ & $0.0 I^{\#}$ \\
\hline PPBS (mg/dl) & $141.64 \pm 19.87$ & $180.19 \pm 59.28$ & $<0.00 I^{\#}$ \\
\hline $\mathrm{HbAlc}(\%)$ & $5.421 \pm 0.706$ & $6.40 \pm 1.63$ & $<0.00 I^{\#}$ \\
\hline Creatinine $(\mathrm{mg} / \mathrm{dl})$ & $1.121 \pm 0.30$ & $1.10 \pm 0.39$ & $0.90^{\#}$ \\
\hline LDL $(\mathrm{mg} / \mathrm{dl})$ & $121.78 \pm 34.42$ & $121.77 \pm 42.05$ & $0.99^{\#}$ \\
\hline $\mathrm{HDL}(\mathrm{mg} / \mathrm{dl})$ & $42.357 \pm 6.640$ & $40.02 \pm 11.19$ & $0.29^{*}$ \\
\hline Vitamin D (ng/ml) & $25.942 \pm 11.638$ & $26.078 \pm 12.905$ & $0.96^{\#}$ \\
\hline
\end{tabular}

\#independent t-test, *chi-square test. FBS: Fasting blood sugar, PPBS: Postprandial blood sugar, HDL: High density lipoprotein, LDL: Low density lipoprotein, ACS:Acute coronary syndrome, CSA: Chronic stable angina 


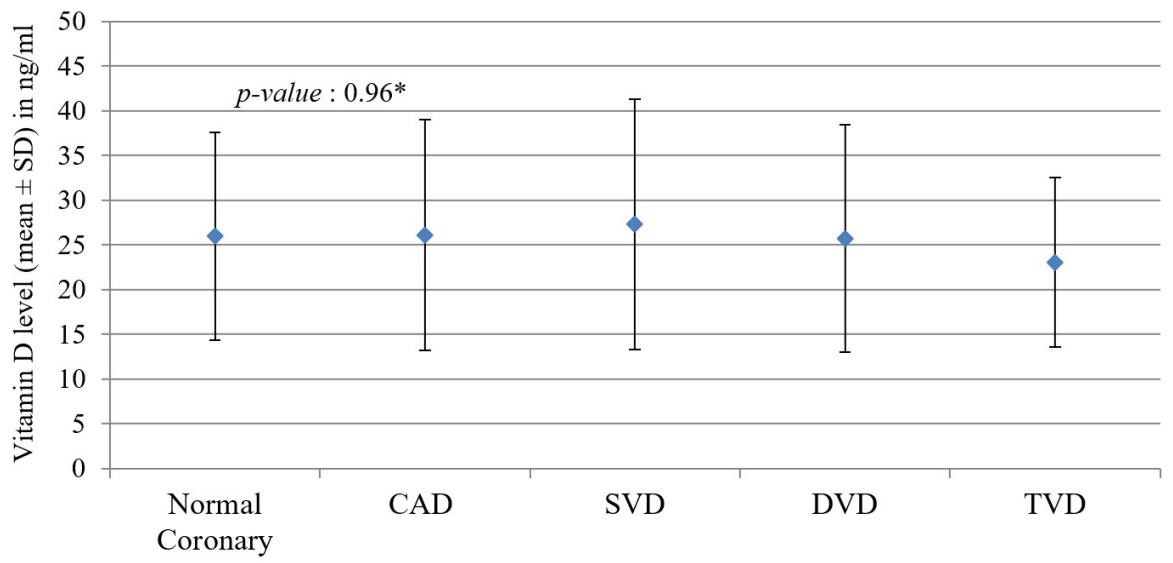

Figure 1: Mean vitamin D level according to coronary angiography profile $(n=106) .{ }^{*} p$-value comparing normal coronary and CAD. CAD: Coronary artery disease, SVD: Single vessel disease, DVD: Double vessel disease, TVD: Triple vessel disease

patients with angiographic proven CAD (75\%) was comparable $(\mathrm{p}=0.39)$ to that of patients with angiographic normal coronary artery $(64.3 \%)$. The frequency of vitamin D deficiency in SVD, DVD and TVD patients were 68.6\%, 78.3\% and 88.9\% respectively $(\mathrm{p}=0.21)($ Table 2).

Out of 74 patients of ACS, 56 (75.7\%) patients had vitamin D deficiency and 18 (24.3\%) had normal vitamin D level. Similarly, out of 32 patients of CSA, 22 (68.8\%) patients had vitamin D deficiency and 10 (31.3\%) had normal vitamin D level (Fig. 2).

\section{DISCUSSION}

$\mathrm{W}$ e found that out of 106 patients, 86.8\% had angiographic proven $\mathrm{CAD}$ and $13.2 \%$ had angiographic normal coronary artery. The prevalence of vitamin D deficiency in angiographic proven CAD group (75\%) and angiographic normal coronary artery (64.3\%) were comparable. In addition, vitamin $\mathrm{D}$ deficiency was not associated with severity of angiographic proven CAD.

High prevalence of vitamin D deficiency in our population is reflective of the generalized high prevalence rates of hypovitaminosis D in Nepal [9]. The high prevalence rates in our country despite its sunny climate and darker skin complexion of the population may be due to generalized malnutrition, vegetarian food habits, inadequate sun exposure, and lack of vitamin D food fortification program.

Multiple studies showed that vitamin D deficiency is directly or indirectly associated with $\operatorname{CAD}[19,20]$. Recent meta-analyses have been conflicting, with both positive and neutral associations reported [21, 22]. Moreover, data on severity of vitamin D deficiency and extent of angiographically determined CAD are limited.

In our study, the prevalence of vitamin D deficiency was high in both angiographic proven CAD group and angiographically normal coronary artery (75\% vs $64.3 \%)$. In addition, there was no statistically significant difference in the prevalence of vitamin D deficiency among SVD, DVD and TVD patients. However, there was a trend towards lower mean vitamin $\mathrm{D}$ level with increasing severity of CAD. Further study with a larger

Table 2: Prevalence of vitamin D deficiency among patients with various coronary angiography profiles ( $n=106)$. Values are expressed as $n$ (\%)

\begin{tabular}{llll}
\hline Coronary angiography profile & $\begin{array}{l}\text { Vitamin } D<30 \mathrm{ng} / \mathrm{ml} \\
(\mathrm{n}=78)\end{array}$ & $\begin{array}{l}\text { Vitamin } \mathrm{D} \geq 30 \mathrm{ng} / \mathrm{ml} \\
(\mathrm{n}=28)\end{array}$ & -value $^{*}$ \\
\hline Normal Coronary $(\mathrm{n}=14)$ & $9(64.3 \%)$ & $5(35.7 \%)$ & 0.39 \\
CAD $(\mathrm{n}=92)$ & $69(75 \%)$ & $23(25 \%)$ & \\
SVD $(\mathrm{n}=5 \mathrm{I})$ & $35(68.6 \%)$ & $16(31.4 \%)$ & 0.21 \\
DVD $(\mathrm{n}=23)$ & $18(78.3 \%)$ & $5(21.7 \%)$ & \\
TVD $(\mathrm{n}=18)$ & $16(88.9 \%)$ & $2(11.1 \%)$ & \\
\hline
\end{tabular}

* chi-square test. CAD: Coronary artery disease, SVD: Single vessel disease, DVD: Double vessel disease,TVD:Triple vessel disease. 

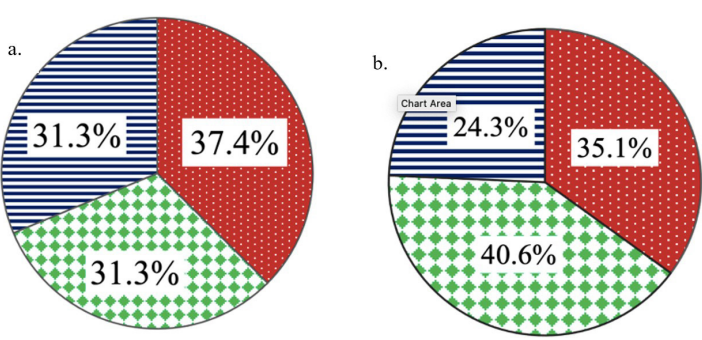

$<20 \mathrm{ng} / \mathrm{ml} \otimes 20-30 \mathrm{ng} / \mathrm{ml}$ 目 $\geq 30 \mathrm{ng} / \mathrm{ml}$

Figure 2: Vitamin $D$ level in patients with a. chronic stable angina $(n=32)$, b. acute coronary syndrome $(n=74)$

sample size may be able to demonstrate an association.

Among the patients undergoing CAG in Ludwigshafen Risk and Cardiovascular Health study cohort, low levels of vitamin D were independently associated with heart failure, all-cause and cardiovascular mortality. However, the relationship between vitamin $\mathrm{D}$ and angiographic severity of CAD was not reported $[23,24]$. A higher prevalence of vitamin D deficiency in angiographically proven $\mathrm{CAD}$ patients and positive association with severity of CAD with vitamin D deficiency have been reported, but the study lacked a control group [25]. Similarly, a study reported lower vitamin D levels in patients with CAD than in controls and also re- vealed protective association of vitamin $\mathrm{D}$ with $\mathrm{CAD}$ after adjusting for conventional risk factors [26]. Similar to our study, an Indian study revealed a high prevalence of vitamin D deficiency in patients with CAD (81.70\%) and no association of vitamin $\mathrm{D}$ deficiency with angiographic severity of CAD [27]. Comparable to our study, prevalence of vitamin D deficiency was $64.7 \%$ in patients with ACS and mean vitamin D level was $27.99 \pm$ $11.77 \mathrm{ng} / \mathrm{ml}$ in another study [28].

Our study had several limitations. Firstly, our sample size was small and the study was restricted to a single center. Secondly, we did not have outcome-related data. Thirdly, we took patient with angiographic normal coronary group as control which was disproportionately small in size. Perhaps, an age matched cohort who attended cardiac outpatient department with no signs/ symptoms suggestive of ischemia could have been a better control group for comparison. Fourthly, it is very difficult to prove association of vitamin D deficiency with CAD in a population, where prevalence of vitamin D deficiency is itself very high.

\section{CONCLUSION}

The prevalence of vitamin D deficiency in both angiographic normal coronary artery and angiographic proven $\mathrm{CAD}$ were high but comparable. There was no association of vitamin D deficiency with severity of angiographic proven CAD.

\section{References}

I. Granger CB, Goldberg RJ, Dabbous O, Pieper KS, Eagle KA, Cannon CP, et al. Global Registry of Acute Coronary Events Investigators. Predictors of hospital mortality in the global registry of acute coronary events. Arch Intern Med. 2003;163(19):2345-53. DOI: 10.100I/archinte.163.19.2345.

2. Ford ES, Ajani UA, Croft JB, Critchley JA, Labarthe DR, Kottke TE, et al. Explaining the decrease in U.S. deaths from coronary disease, 1980-2000. N Engl J Med. 2007;356[23]:2388-98. DOI: 10.1056/ NEJMsa053935.

3. Lee JH, O'Keefe JH, Bell D, Hensrud DD, Holick MF. Vitamin D deficiency an important, common, and easily treatable cardiovascular risk factor? J Am Coll Cardiol. 2008;52(24):1949-56. DOI: I0.10|6/j.jacc.2008.08.050.

4. Judd SE, Tangpricha V. Vitamin D deficiency and risk for cardiovascular disease. Am J Med Sci. 2009;338(I):40-4. DOI: I0.1097/ MAJ.0b0I3e3I8Iaaee9I.

5. Holick MF.Vitamin D deficiency. N EngI J Med. 2007;357(3):266-8I. DOI: 10.1056/NEJMra070553.

6. Weishaar RE, Kim SN, Saunders DE, Simpson RU. Involvement of vitamin D3 with cardiovascular function. III. Effects on physical and morphological properties.Am J Physiol. 1990;258(I Pt I):EI34-42. DOI: I0.I I52/ajpendo.1990.258.I.EI34.

7. Loftus IM, Thompson MM. The role of matrix metalloprotein- ases in vascular disease. Vasc Med. 2002;7(2):I17-33. DOI: 10.1191//358863x02vm420ra.

8. Kong J, Kim GH, Wei M, Sun T, Li G, Liu SQ et al. Therapeutic effects of vitamin $D$ analogs on cardiac hypertrophy in spontaneously hypertensive rats. Am J Pathol. 2010; I77(2):622-3I. DOI: I0.2353/ajpath.2010.09I292.

9. Rai CK, Shrestha B, Sapkota J, Das JK. Prevalence of vitamin D deficiency among adult patients in a tertiary care hospital. JNMA J Nepal Med Assoc. 2019;57(2 I8):226-8. DOI: 10.3I729/jnma.4534

10. Akhtar T, Aggarwal R, Jain SK. Serum Vitamin D level in patients with coronary artery disease and association with eun Exposure: experience from a tertiary care, teaching hospital in India. Adv Med. 2019;2019:68234I7. DOI: I0.II55/2019/68234I7.

II. Kaur S, Kaur H, Sharma S, Bhatia A. Prevalence of vitamin D deficiency in patients with established coronary artery disease. Int J Res Med Sci. 2020;8. DOI: I0.18203/2320-60 I2.jirms2020I5I3

12. Joshi P, Islam S, Pais P, Reddy S, Dorairaj P, Kazmi K, et al. Risk factors for early myocardial infarction in South Asians compared with individuals in other countries. JAMA. 2007;297(3):286-94. DOI: 10.100I/jama.297.3.286.

13. Scanlon PJ, Faxon DP, Audet AM, Carabello B, Dehmer GJ, Eagle $\mathrm{KA}$, et al.ACC/AHA guidelines for coronary angiography.A report of the American College of Cardiology/American Heart Associ- 
ation Task Force on practice guidelines (Committee on Coronary Angiography). Developed in collaboration with the Society for Cardiac Angiography and Interventions. J Am Coll Cardiol. 1999;33(6): 1756-824. DOI: 10.1016/s0735-1097(99)00I26-6.

14. Luepker RV, Apple FS, Christenson RH, Crow RS, Fortmann SP, Goff D, et al. Case definitions for acute coronary heart disease in epidemiology and clinical research studies: a statement from the AHA Council on Epidemiology and Prevention;AHA Statistics Committee; World Heart Federation Council on Epidemiology and Prevention; European Society of Cardiology Working Group on Epidemiology and Prevention; Centers for Disease Control and Prevention; National Heart, Lung, and Blood Institute. Case definitions for acute coronary heart disease in epidemiology and clinical research studies: a statement from the AHA Council on Epidemiology and Prevention; AHA Statistics Committee; World Heart Federation Council on Epidemiology and Prevention; the European Society of Cardiology Working Group on Epidemiology and Prevention; Centers for Disease Control and Prevention; and the National Heart, Lung, and Blood Institute. Circulation. 2003;I08(20):2543-9. DOI: I0.II6I/0I.CIR.0000I00560.46946. EA.

15. Whelton PK, Carey RM, Aronow WS, Casey DE Jr, Collins KJ, Dennison Himmelfarb C, et al. 2017 ACC/AHA/AAPA/ABC/ ACPM/AGS/APhA/ASH/ASPC/NMA/PCNA Guideline for the prevention, detection, evaluation, and management of high blood pressure in adults: executive summary:A Report of the American College of Cardiology/American Heart Association Task Force on Clinical Practice Guidelines. J Am Coll Cardiol. 2018;7I(19):219969. DOI: 10.1016/j.jacc.2017.11.005.

16. American Diabetes Association. Standards of medical care in diabetes-2017 abridged for primary care providers. Clin Diabetes. 2017;35(I):5-26. DOI: 10.2337/cdI 6-0067.

17. Jellinger PS, Handelsman Y, Rosenblit PD, Bloomgarden ZT, Fonseca VA, Garber AJ, et al. American Association of Clinical Endocrinologists and American College of Endocrinology Guidelines for management of dyslipidemia and prevention of cardiovascular disease. Endocr Pract. 2017;23(Suppl 2):I-87. DOI: 10.4I58/ EPI7I764.APPGL.

18. Centers for Disease Control and Prevention. Best Practices for Comprehensive Tobacco Control Programs-2007. Atlanta: U.S. Department of Health and Human Services, Centers for Disease Control and Prevention, National Center for Chronic Disease Prevention and Health Promotion, Office on Smoking and Health; October 2007.
19. Jablonski KL, Chonchol M, Pierce GL,Walker AE, Seals DR. 25-Hydroxyvitamin $D$ deficiency is associated with inflammation-linked vascular endothelial dysfunction in middle-aged and older adults. Hypertension. 201 I;57(I):63-9. DOI: 10.1 I6I/HYPERTENSIONAHA.II 0.160929 .

20. Reddy Vanga S, Good M, Howard PA, Vacek JL. Role of vitamin D in cardiovascular health. Am J Cardiol. 20 I0; 106(6):798-805. DOI: 10.1016/j.amjcard.2010.04.042.

2I. Autier P, Gandini S.Vitamin D supplementation and total mortality: a meta-analysis of randomized controlled trials. Arch Intern Med. 2007;167(16):1730-7. DOI: 10.100I/archinte.167.16.1730.

22. Grandi NC, Breitling LP, Brenner H. Vitamin D and cardiovascular disease: systematic review and meta-analysis of prospective studies. Prev Med. 2010;5I(3-4):228-33. DOI: 10.1016/j. ypmed.2010.06.013.

23. Dobnig H, Pilz S, Scharnagl H, Renner W, Seelhorst U, Wellnitz, et al. Independent association of low serum 25-hydroxyvitamin $\mathrm{d}$ and I,25-dihydroxyvitamin $\mathrm{d}$ levels with all-cause and cardiovascular mortality. Arch Intern Med. 2008;168(I2):I340-9. DOI: 10.1001/archinte.168.12.1340.

24. Pilz S, März W, Wellnitz B, Seelhorst U, Fahrleitner-Pammer A, Dimai HP, et al.Association of vitamin $D$ deficiency with heart failure and sudden cardiac death in a large cross-sectional study of patients referred for coronary angiography. J Clin Endocrinol Metab. 2008;93(I0):3927-35. DOI: 10.121 0/jc.2008-0784.

25. Syal SK, Kapoor A, Bhatia E, Sinha A, Kumar S, Tewari S, et al.Vitamin $\mathrm{D}$ deficiency, coronary artery disease, and endothelial dysfunction: observations from a coronary angiographic study in Indian patients. J Invasive Cardiol. 2012;24(8):385-9. PMID: 22865308.

26. Shanker J, Maitra A, Arvind P, Nair J, Dash D, Manchiganti R, et al. Role of vitamin $D$ levels and vitamin $D$ receptor polymorphisms in relation to coronary artery disease: the Indian atherosclerosis research study. Coron Artery Dis. 20I I;22(5):324-32. DOI: I0.1097/MCA.0b0I3e3283472a57.

27. Dhibar DP, Sharma YP, Bhadada SK, Sachdeva N, Sahu KK. Association of vitamin $D$ deficiency with coronary artery disease. J Clin Diagn Res. 2016;10(9):OC24-OC28. DOI: 10.7860/ JCDR/2016/227/8.8526.

28. Nepal R, Karki P, Uraw S, Lamsal M. Prevalence of vitamin D deficiency among patients of acute coronary syndrome in a tertiary care center of Eastern Nepal. J Nepal Med Assoc. 2021;59(235). DOI: $10.31729 /$ jnma.5166 